\title{
Qualidade da madeira e do carvão vegetal oriundos de floresta plantada em Minas Gerais
}

Thiago de Paula Protásio¹, Selma Lopes Goulart ${ }^{1}$, Thiago Andrade Neves², Paulo Fernando Trugilho ${ }^{1}$, Fernanda Maria Guedes Ramalho $^{3}$, Lívia Mara Rodrigues de Souza Brites Queiroz ${ }^{3}$

\author{
1 Universidade Federal de Lavras, Departamento de Ciências Florestais/Ciência e Tecnologia da Madeira, CEP 37200-000, CP 3037, Lavras, MG, Brasil \\ ${ }^{2}$ Brasil Saint-Gobain Canalizações LTDA, Rua Corrêa Lacerda, 33, CEP 37310-000, Bom Jardim de Minas, MG, Brasil \\ ${ }^{3}$ Universidade Federal de Minas Gerais, Instituto de Ciências Agrárias, CEP 39404-547, Montes Claros, MG, Brasil
}

"Autor correspondente:

depaulaprotasio@gmail.com

Termos para indexação:

Eucalyptus spp.

Energia de biomassa

Carbonização

Combustão

Index terms:

Eucalyptus spp.

Biomass energy

Carbonization

Combustion

Histórico do artigo:

Recebido em 04/02/2014

Aprovado em 10/06/2014

Publicado em 07/07/2014

doi: 10.4336/2014.pfb.34.78.657
Resumo - O objetivo deste trabalho foi avaliar a qualidade da madeira e do carvão vegetal oriundos de árvores jovens de Eucalyptus spp., bem como verificar a influência da idade e clone no desempenho energético desses combustíveis. Foram amostrados os clones 1277 e 0321 de Eucalyptus spp. em duas idades (46 e 58 meses). Na madeira foram determinadas as características químicas moleculares e elementares, a densidade básica, os estoques de carbono e lignina por volume, as densidades energéticas e os poderes caloríficos (superior e inferior). $\mathrm{O}$ carvão vegetal foi produzido em um forno elétrico (mufla) com temperatura final de $450^{\circ} \mathrm{C}$. Foi realizado o balanço de massa e energia das carbonizações, além da avaliação da composição química imediata, densidade aparente e poderes caloríficos do carvão vegetal produzido. O clone 1277, na idade de 58 meses, é o mais indicado para a produção de carvão vegetal siderúrgico e combustão direta da madeira, pois apresentou melhores resultados para a densidade básica, densidades energéticas, estoques de carbono e lignina por unidade de volume e para o teor de lignina da madeira. O efeito clonal e da idade não influenciou os teores de carbono fixo e materiais voláteis, os poderes caloríficos, o rendimento em carvão vegetal e as perdas energéticas da carbonização.

\section{Wood and charcoal quality from planted forest in Minas Gerais State, Brazil}

\begin{abstract}
The objective of this study was to evaluate the wood and charcoal quality of young Eucalyptus spp. trees, and to verify the influence of age and clone on the energy performance of these fuels. It was sampled the clones 1277 and 0321 of Eucalyptus spp. in two ages (46 and 58 months). The characteristics determined in the wood were: chemical molecular and elementary, basic density, carbon stocks and lignin by volume, the energy density and heating values (higher and lower). The charcoal was produced in an electric furnace (muffle) with the final temperature of $450^{\circ} \mathrm{C}$. It was conducted the mass balance and carbonization energy, beyond the immediate evaluation of the chemical composition, apparent density and calorific value of charcoal. The clone 1277, at the age 58 months, is the most suitable for the charcoal production for steel industry and direct combustion of wood, because it showed better results for basic density, energy density, carbon stocks and lignin per unit volume and the lignin content of the wood. The clonal effect and age did not influence the content of fixed carbon and volatile materials, the calorific values, the gravimetric yield in charcoal and energy losses of carbonization.
\end{abstract}




\section{Introdução}

Atualmente, tem-se evidenciado um aumento do consumo de carvão de vegetal proveniente das florestas plantadas, principalmente do gênero Eucalyptus, em função da necessidade de redução e eliminação do uso de carvão vegetal de florestas nativas. Além disso, segundo a Associação Brasileira de Produtores de Florestas Plantadas (ABRAF) (Anuário..., 2013), a substituição de carvão mineral pelo carvão vegetal possibilita a mitigação das emissões de dióxido de carbono na siderurgia brasileira.

Nesse sentido, o Brasil se destaca como o maior produtor de carvão vegetal no mundo, sendo que os maiores consumidores são os setores de ferro-gusa, aço e ferros-liga. Contudo, esse biocombustível representa apenas $19,9 \%$ da matriz energética dos setores de ferrogusa e aço, enquanto o coque de carvão mineral representa 44,6\% (Empresa de Pesquisa Energética, 2013).

Dessa forma, há uma necessidade de aumento da participação do carvão vegetal proveniente da madeira de florestas plantadas na siderurgia brasileira, principalmente por meio da seleção de clones jovens de Eucalyptus, visando aumentar a produtividade desse biorredutor que atenda às especificações industriais.

No entanto, deve-se levar em consideração os efeitos da idade (Assis et al., 2012; Neves et al., 2013) e de clone (Neves et al., 2011; Santos et al., 2011; Pereira et al., 2012; Santos et al., 2012a; Castro et al., 2013; Couto et al., 2013; Pereira et al., 2013b; Protásio et al., 2013c) na qualidade da madeira, principalmente em árvores jovens que apresentam a predominância de madeira juvenil. Isso poderá afetar consideravelmente as rotas de conversão energética da madeira, especialmente a pirólise lenta (Santos et al., 2012b; Pereira et al., 2013a) e a combustão direta.

Por isso, a análise e interpretação das características da madeira de árvores jovens de Eucalyptus, no contexto de florestas energéticas, merece destaque. A compreensão da qualidade dessa matéria-prima poderá contribuir para o melhoramento genético voltado à seleção de materiais superiores para a otimização da produção de carvão vegetal siderúrgico ou geração direta de calor nas caldeiras para aquecimento ou obtenção de vapor.

O objetivo deste trabalho foi avaliar a qualidade da madeira e do carvão vegetal oriundos de árvores jovens de Eucalyptus spp., bem como verificar a influência da idade e clone no desempenho energético desses combustíveis.

\section{Material e métodos}

\section{Material biológico e amostragem}

Foram amostrados dois clones de Eucalyptus spp. (0321 e 1277), desenvolvidos pela empresa Copener Bahia, oriundos dos plantios comerciais da Saint-Gobain Pam Bioenergia LTDA., localizada no Município de Lima Duarte, Estado de Minas Gerais, em duas idades (46 e 58 meses - Tabela 1) e instalados em espaçamento de plantio de 3,5 $\mathrm{m} \times 2,5 \mathrm{~m}$. Na época da coleta, a região apresentava temperatura e precipitação média de $20,4^{\circ} \mathrm{C}$ e $1.250 \mathrm{~mm}$, respectivamente.

Tabela 1. Características dendrométricas dos clones de Eucalyptus spp. avaliados.

\begin{tabular}{ccccc}
\hline Clone & $\begin{array}{c}\text { Idade } \\
\text { (meses) }\end{array}$ & $\begin{array}{c}\text { Diâmetro à } \\
\text { altura do peito } \\
\text { (DAP cm) }\end{array}$ & $\begin{array}{c}\text { Altura } \\
\text { total } \\
\text { (Ht m) }\end{array}$ & $\begin{array}{c}\text { Altura } \\
\text { comercial } \\
\text { (Hc m) }\end{array}$ \\
\hline 0321 & 46 & $12,5^{( \pm 1,83)}$ & $14,88^{( \pm 1,31)}$ & $10,98^{( \pm 1,44)}$ \\
1277 & 46 & $12,4^{( \pm 1,35)}$ & $\left.14,45^{( \pm 0,61}\right)$ & $11,08^{( \pm 0,82)}$ \\
\hline 0321 & 58 & $14,1^{( \pm 0,20)}$ & $17,08^{( \pm 0,56)}$ & $14,73^{( \pm 0,34)}$ \\
1277 & 58 & $12,6^{( \pm 1,39)}$ & $14,28^{( \pm 0,62)}$ & $11,78^{( \pm 0,73)}$ \\
\hline
\end{tabular}

"Valores entre parênteses referem-se ao desvio padrão amostral.

Foi realizada a fosfatagem $\left(450 \mathrm{~kg} \mathrm{ha}^{-1}\right)$ na subsolagem e a aplicação de $171 \mathrm{~kg} \mathrm{ha}^{-1}$ de NPK 06-30-15 com 0,5\% de $\mathrm{B}, 0,3 \%$ de $\mathrm{Zn}$ e $0,3 \%$ de $\mathrm{Cu}, 10$ a 20 dias após o transplantio das mudas. Além disso, foram aplicados $228 \mathrm{~kg} \mathrm{ha}^{-1}$ de cloreto de potássio nos dois primeiros anos do plantio.

Foram amostradas de forma casual um total de dezesseis árvores, sendo quatro árvores de cada clone em cada idade, e retirados discos de $2,5 \mathrm{~cm}$ de espessura a 2, 10, 30, 50 e 70\% da altura comercial da árvore (considerada até um diâmetro mínimo de $5 \mathrm{~cm}$ com casca), além de um disco extra a 1,30 m de altura do solo (DAP), conforme diretrizes de Downes et al. (1997).

\section{Análises químicas, físicas e energéticas da madeira}

Os discos retirados das árvores foram seccionados em quatro cunhas, passando pela medula. As duas cunhas opostas menores foram utilizadas na determinação da densidade básica da madeira (DBM), seguindo as prescrições da NBR 11941 (Associação Brasileira de Normas Técnicas, 2003a). A densidade básica média da árvore foi considerada como sendo a média aritmética dos pontos de amostragem longitudinal no tronco das árvores, sem considerar o DAP. 
Para a determinação do poder calorífico superior (PCS), dos teores de lignina, extrativos totais, cinzas e dos componentes elementares $(\mathrm{C}, \mathrm{H}, \mathrm{N}, \mathrm{S}$ e $\mathrm{O})$ foram retiradas amostras nos discos, por meio de uma plaina elétrica manual, visando à formação de uma amostra composta por árvore. Posteriormente, as maravalhas foram reduzidas a pó em um moinho de facas tipo Willey.

O teor de lignina insolúvel (Klason) foi obtido de acordo com a metodologia proposta por Gomide \& Demuner (1986) e o teor de lignina solúvel (Klason) foi determinado utilizando-se a metodologia proposta por Goldschimid (1971). Dessa forma, o teor de lignina total consiste no somatório dos teores de lignina solúvel e insolúvel.

Para a quantificação dos teores de cinzas e extrativos totais da madeira foram consideradas as metodologias previstas na NBR 13999 (Associação Brasileira de Normas Técnicas, 2003b) e NBR 14853 (Associação Brasileira de Normas Técnicas, 2010), respectivamente. O teor de holocelulose foi calculado por diferença em relação aos demais componentes moleculares e minerais da madeira.

Para a análise química elementar, as amostras foram moídas e peneiradas, sendo utilizada a fração que passou pela peneira de 200 mesh e ficou retida na peneira de 270 mesh. A quantificação dos teores de carbono (C), hidrogênio $(H)$, nitrogênio $(N)$ e enxofre $(S)$ em relação à massa seca da madeira foi realizada em um analisador universal da marca Elementar (modelo Vario Micro Cube) em duplicata. O teor de oxigênio foi obtido por diferença (Equação 1). Adicionalmente, foram calculadas as relações $\mathrm{C} / \mathrm{N}$ e $\mathrm{C} / \mathrm{H}$ da madeira.

$\mathrm{O}(\%)=100-\mathrm{C}(\%)-\mathrm{H}(\%)-\mathrm{N}(\%)-\mathrm{S}(\%)-\mathrm{Cinzas}(\%)(1)$

$\mathrm{O}$ poder calorífico superior (PCS) foi determinado em um calorímetro digital IKA ${ }^{\circledR}$ C-200, conforme a NBR 8633 (Associação Brasileira de Normas Técnicas, 1984). O poder calorífico inferior (PCI) foi estimado com base na Equação 2, desconsiderando a quantidade de energia necessária para evaporar a água formada durante a combustão da madeira.

$\mathrm{PCI}=\mathrm{PCS}-(600 \times 9 \mathrm{H} / 100)$

Em que: PCI é o poder calorífico inferior $\left(\mathrm{kcal} \mathrm{kg}^{-1}\right)$; PCS é o poder calorífico superior $\left(\mathrm{kcal} \mathrm{kg}^{-1}\right)$ e $\mathrm{H}$ é o teor de hidrogênio $(\%)$.

Foram determinadas as densidades energéticas da madeira base PCS $\left(\mathrm{DE}_{\mathrm{PCS}}\right)$ e base $\mathrm{PCI}\left(\mathrm{DE}_{\mathrm{PCI}}\right)$ por meio do produto da densidade básica média (DBM) pelos poderes caloríficos superior (PCS) e inferior (PCI), respectivamente.
$\mathrm{O}$ estoque de carbono na madeira por unidade de volume (ECM) foi obtido multiplicando-se o teor de carbono da madeira pela densidade básica média (DBM).

De forma semelhante, foi determinado o estoque de lignina total na madeira por unidade de volume (ELIGM) multiplicando-se a densidade básica média pelo teor de lignina total.

\section{Carbonizações e avaliação do carvão vegetal}

As carbonizações laboratoriais foram realizadas em um forno elétrico (mufla) conectado a um condensador resfriado à água, o qual é acoplado a um frasco coletor de gases condensáveis. Foi selecionada uma árvore representativa, com densidade básica mais próxima da densidade básica média do clone em questão, para ser carbonizada. Esse procedimento também foi realizado por Protásio et al. (2013b).

Foram utilizados em cada ensaio aproximadamente $500 \mathrm{~g}$ de madeira das cunhas provenientes dos discos retirados das árvores. As amostras foram previamente secas em estufa a $103 \pm 2{ }^{\circ} \mathrm{C}$. A temperatura inicial da carbonização foi de $100{ }^{\circ} \mathrm{C}$ e a temperatura final de $450{ }^{\circ} \mathrm{C}$, considerando-se uma taxa de aquecimento de $1,67^{\circ} \mathrm{C} \min ^{-1}\left(100^{\circ} \mathrm{C} \mathrm{h}^{-1}\right)$. O forno elétrico permaneceu estabilizado a $450^{\circ} \mathrm{C}$ por $30 \mathrm{~min}$, conforme utilizado por outros autores (Neves et al., 2011; Pereira et al., 2013b; Protásio et al., 2012; 2013b).

Após as carbonizações, foram avaliados os rendimentos em carvão vegetal (RGC), líquido pirolenhoso (RLP) e, por diferença, em gases não condensáveis (RGNC).

Também foram calculados os rendimentos energéticos da carbonização tendo como base o PCS $\left(\mathrm{RE}_{\mathrm{PCS}}\right)$ e o PCI $\left(\mathrm{RE}_{\mathrm{PCI}}\right)$, conforme apresentado nas Equações 3 e 4.

$\mathrm{RE}_{\mathrm{PCS}}=\mathrm{RGCx}\left(\mathrm{PCS}_{\text {carvão }} / \mathrm{PCS}_{\text {madeira }}\right)$

$\mathrm{RE}_{\mathrm{PCI}}=\mathrm{RGC} \times\left(\mathrm{PCI}_{\text {carvão }} / \mathrm{PCI}_{\text {madeira }}\right)$

Em que: RGC é o rendimento gravimétrico em carvão vegetal (\%); $\mathrm{PCS}_{\text {carvão }}$ e $\mathrm{PCI}_{\text {carvão }}$ são os poderes caloríficos superior e inferior do carvão vegetal $\left(\mathrm{kcal} \mathrm{kg}^{-1}\right)$, respectivamente; $\mathrm{PCS}_{\text {madeira }}$ e $\mathrm{PCI}_{\text {madeira }}$ são os poderes caloríficos superior e inferior da madeira $\left(\mathrm{kcal} \mathrm{kg}^{-1}\right)$.

A densidade relativa aparente (DRA) do carvão vegetal foi determinada de acordo com o método hidrostático, por meio de imersão em água, conforme descrito na NBR 11941 (Associação Brasileira de Normas Técnicas, 2003a). 
Para a determinação do poder calorífico superior, do poder calorífico inferior e do teor de hidrogênio foram considerados os mesmos procedimentos realizados para a madeira, sendo os ensaios realizados em duplicata. De forma semelhante, foram determinadas as densidades energéticas do carvão $\left(\mathrm{DE}_{\mathrm{PCS}}\right.$ e $\left.\mathrm{DE}_{\mathrm{PCI}}\right)$.

Foi realizada também em duplicata, a análise química imediata nos carvões produzidos visando à determinação dos teores de umidade, materiais voláteis (TMV), cinzas (TCZ) e, por diferença, de carbono fixo (TCF), conforme procedimento estabelecido na norma D176284 (American Society for Testing and Materials, 2007).

$\mathrm{O}$ estoque em carbono fixo (ECF) no carvão vegetal por unidade de volume foi calculado multiplicando-se a densidade relativa aparente pelo teor de carbono fixo no carvão, de forma análoga à realizada por Protásio et al. (2013b). Além disso, foi calculado o rendimento em carbono fixo (RCF) pelo produto entre o rendimento gravimétrico em carvão vegetal pelo teor de carbono fixo.

\section{Análises estatísticas}

Na avaliação das características quantificadas na madeira utilizou-se o delineamento inteiramente casualizado (DIC) disposto em um esquema fatorial $2 \times 2$, considerando-se como níveis dos fatores os diferentes clones e as idades com 4 repetições. Os níveis de significância considerados para o teste $\mathrm{F}$ foram de $1 \%$ e $5 \%$.

Para as propriedades do carvão vegetal foi realizada a análise de componentes principais (PCA), visando identificar o efeito de clone e idade na qualidade e rendimentos desse biorredutor. Para isso, foram consideradas apenas as seguintes variáveis: densidade relativa aparente; rendimentos gravimétricos em carvão vegetal, líquido pirolenhoso e gases não condensáveis; poder calorífico superior e teores de cinzas, carbono fixo e materiais voláteis. Essas variáveis são consideradas as mais importantes, pois por meio delas é possível obter as demais propriedades analisadas.

A técnica multivariada de componentes principais foi efetuada considerando apenas as médias padronizadas, ou seja, com variância unitária.

Todas as análises estatísticas foram efetuadas utilizando o software R versão 3.0.1 (R Core Team, 2013) por meio dos pacotes estatísticos ExpDes (Ferreira et al., 2013) e stats (R Core Team, 2013).

\section{Resultados e discussão}

\section{Análise da interação clone $x$ idade para as características da madeira}

Observa-se efeito da interação entre clone $\mathrm{x}$ idade para a densidade básica, estoques de carbono e lignina total por unidade de volume, teores de lignina total e holocelulose e para as densidades energéticas (Tabela 2), evidenciando assim a existência de dependência entre os fatores considerados. Dessa forma, procedeu-se o desdobramento de clone dentro de idade e idade dentro de clone, visando selecionar o melhor material genético em uma idade específica.

Esses parâmetros avaliados na madeira (Tabela 2) são considerados fundamentais para a seleção de clones de Eucalyptus para a produção de bioenergia, especialmente para a produção de carvão vegetal e para a combustão direta (Santos et al., 2011, 2012b; Pereira et al., 2012; 2013b; Neves et al., 2013; Protásio et al., 2013c).

Tabela 2. Resumo das análises de variância para as características da madeira de Eucalyptus spp. que apresentaram efeito da interação clone x idade.

\begin{tabular}{ccccccccc}
\hline \multirow{2}{*}{ Fator de variação } & \multirow{2}{*}{ GL } & \multicolumn{7}{c}{ Quadrado médio } \\
\cline { 3 - 8 } & & DB & ECM & ELIG & Holo & Lig & DE $_{\mathbf{P C S}}$ & DE $_{\mathbf{P C I}}$ \\
\hline Clone & 1 & $2413,57^{*}$ & $238,70^{\text {ns }}$ & $2,87^{\text {ns }}$ & $7,31^{\text {ns }}$ & $3,22^{\text {ns }}$ & $0,063^{*}$ & $0,057^{*}$ \\
Idade & 1 & $19556,65^{*}$ & $1844,27^{*}$ & $6256,43^{*}$ & $186,90^{*}$ & $67,28^{*}$ & $0,470^{*}$ & $0,472^{*}$ \\
Clone* Idade & 1 & $11980,20^{*}$ & $2467,38^{*}$ & $3160,58^{*}$ & $28,11^{*}$ & $28,14^{*}$ & $0,230^{*}$ & $0,198^{*}$ \\
Resíduo & 12 & 148,39 & 56,56 & 54,42 & 1,73 & 1,77 & 0,004 & 0,0038 \\
\hline Média geral & - & 471 & 219 & 138 & 66 & 29 & 2,18 & 2,02 \\
\hline CVe (\%) & - & 2,59 & 3,43 & 5,36 & 1,99 & 4,59 & 3,01 & 3,06 \\
\hline
\end{tabular}

$\mathrm{GL}=$ graus de liberdade; $\mathrm{DB}=$ densidade básica $\left(\mathrm{kg} \mathrm{m}^{-3}\right) ; \mathrm{EC}=$ estoque de carbono $\left(\mathrm{kg} \mathrm{m}^{-3}\right) ; \mathrm{ELIG}=$ estoque de lignina $\left(\mathrm{kg} \mathrm{m}^{-3}\right) ;$ Holo $=$ teor de holocelulose (\%); $\mathrm{Lig}=$ teor de lignina total (\%); $\mathrm{DE}_{\mathrm{PCS}} \mathrm{e} \mathrm{DE}_{\mathrm{PCI}}=$ densidades energéticas base PCS e base PCI $\left(\mathrm{Gcal} \mathrm{m}^{-3}\right)$, respectivamente; $\mathrm{CVe}_{(\%)}=$ coeficiente de variação experimental (\%); *significativo a $1 \%$ pelo teste $\mathrm{F} ; \mathrm{ns}=$ não significativo a $5 \%$ pelo teste $\mathrm{F}$. 
Com base nos resultados encontrados para a densidade básica da madeira (Figura 1), nota-se que, para a idade de 46 meses, o clone 0321 se destacou. Enquanto que para a idade de 58 meses, o clone 1277 apresentou valor estatisticamente superior ao clone 0321 .
As demais características da madeira certamente serão determinantes para a correta avaliação e seleção desses clones, uma vez que a densidade básica não é um parâmetro único de avaliação da potencialidade dos clones de Eucalyptus para a produção de carvão vegetal (Pereira et al., 2013b; Protásio et al., 2013c).
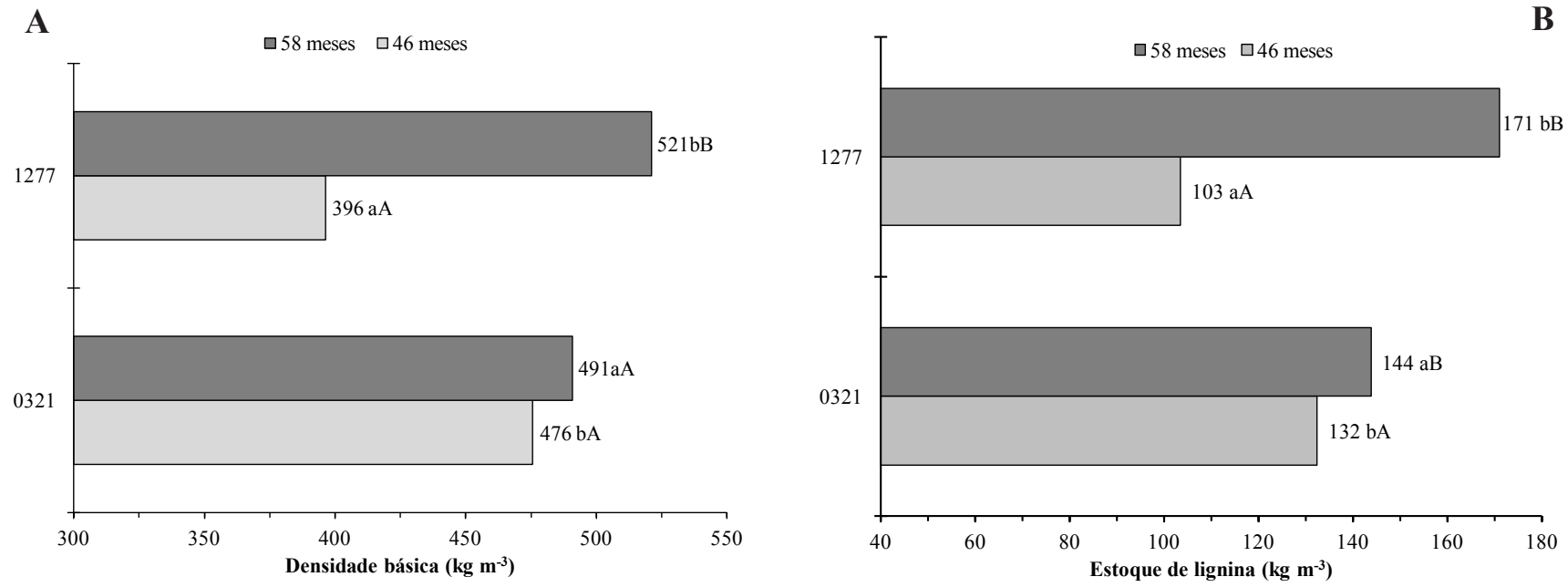

Figura 1. Efeito da interação clone x idade para a (A) densidade básica e (B) estoque de lignina da madeira. Médias seguidas pela mesma letra minúscula referem-se ao desdobramento de clone dentro de cada nível de idade e médias seguidas pela mesma letra maiúscula referem-se ao desdobramento de idade dentro de cada nível de clone, pelo teste $\mathrm{F}(\alpha=0,05)$.

O efeito clonal na densidade básica da madeira também foi constatado por Protásio et al. (2013c). Os autores agruparam clones de Eucalyptus, aos 42 meses de idade, em dois grupos de com médias de $506 \mathrm{~kg} \mathrm{~m}^{-3} \mathrm{e} 561$ $\mathrm{kg} \mathrm{m}^{-3}$, sendo que esses valores são consideravelmente superiores aos resultados desse trabalho. Isso demonstra a necessidade contínua de melhoramento genético das espécies e clones de Eucalyptus plantados no Brasil e destinados ao uso bioenergético, especialmente para a produção de carvão vegetal mais denso, passível de substituir o coque de carvão mineral.

O efeito da idade na densidade básica foi pronunciado apenas para o clone 1277, em que houve um aumento de, aproximadamente, $32 \%$ nessa característica da madeira devido principalmente ao aumento da espessura da parede celular e diminuição do diâmetro do lume das fibras. Resultado semelhante foi encontrado por Neves et al. (2013) para um clone comercial de Eucalyptus spp. nas idades de 55 e 67 meses.
Quando analisado o estoque de lignina na madeira por unidade de volume, o efeito da idade foi percebido para os dois clones avaliados (Figura 1). Contudo, para o clone 1277 o aumento desse parâmetro com a idade foi mais pronunciado, com aproximadamente $66 \%$.

Quanto à influência do fator clone no estoque de lignina, observa-se que na idade de 46 meses o clone 0321 apresentou valor superior ao clone $1277 \mathrm{em}$ aproximadamente $28 \%$; enquanto que na idade de 58 meses ocorreu o contrário, com destaque para o clone 1277.

Dessa forma, considerando os valores de densidade básica e estoque de lignina do clone 1277 na idade de 58 meses, observa-se que esse apresenta potencial de uso bioenergético, especialmente para a otimização da produção de carvão vegetal.

A produtividade de lignina é um importante parâmetro a ser considerado na destinação de clones de Eucalyptus para a carbonização da madeira (Trugilho, 2009), pois 
dentre os elementos químicos moleculares a lignina é o que apresenta maior resistência à degradação térmica (Raad et al., 2006; Yang et al., 2007) e, consequentemente, influencia positivamente o rendimento gravimétrico em carvão vegetal (Protásio et al., 2012). No entanto, a qualidade da lignina (relação siringil/guaiacil) também deve ser considerada nessa avaliação (Pereira et al., 2013b) para o correto uso do clone em questão.

De forma semelhante ao encontrado para a densidade básica, o efeito da idade no estoque de carbono na madeira por unidade de volume foi pronunciado apenas para o clone 1277 (Tabela 3). Na idade de 58 meses o clone 1277 apresentou estoque de carbono superior ao clone 0321.

O estoque de carbono por unidade de volume é uma importante variável, pois considera simultaneamente duas características importantes para a seleção de clones de Eucalyptus para a produção de bioenergia: o teor de carbono e a densidade (Protásio et al., 2013c). Isso reforça a superioridade da madeira do clone 1277 , na idade de 58 meses, como combustível renovável.

$\mathrm{Na}$ literatura é relatada a influência clonal no estoque de carbono da madeira. Protásio et al. (2013c) avaliaram clones de Eucalyptus aos 42 meses de idade e constataram a formação de dois grupos similares com base nessa propriedade, com médias de $231 \mathrm{~kg} \mathrm{~m}^{-3} \mathrm{e}$ $261 \mathrm{~kg} \mathrm{~m}^{-3}$. Esses resultados, de maneira geral, podem ser considerados superiores aos obtidos nesse trabalho. Possivelmente, isso ocorreu devido às diferenças genéticas entre os clones que proporcionaram variações da estrutura química e anatômica da madeira.
Para as densidades energéticas o efeito da idade foi evidenciado pelas análises de variância (Tabela 3). Esse resultado evidencia a importância da seleção e avaliação de clones de Eucalyptus em idades específicas visando otimizar a produção bioenergética, especialmente a combustão direta; visto que quanto maior a densidade energética, maior a disponibilidade de energia por volume. Diante disso, nota-se que na idade de 58 meses o clone 1277 se destacou e apresentou densidades energéticas superiores ao clone 0321.

Para clones de Eucalyptus spp. nas idades de 55 e 67 meses são relatadas na literatura densidades energéticas (base PCS) de 2,05 Gcal m${ }^{-3} \mathrm{e} 2,08 \mathrm{Gcal} \mathrm{m}^{-3}$, respectivamente (Neves et al., 2013), ou seja, valores inferiores aos observados nesse trabalho. Os referidos autores não identificaram efeito da idade nesse parâmetro energético, apesar do aumento considerável no teor de lignina total com a idade. Logo, comparativamente aos valores encontrados por Neves et al. (2013) os clones 0321 e 1277 apresentam potencial de uso como fonte direta de energia.

Quanto aos teores de lignina e holocelulose os clones não diferiram na idade de 46 meses com médias gerais de $27,0 \%$ e $69,4 \%$, respectivamente. Para clones de Eucalyptus sp. aos 42 meses de idade o teor médio de lignina total relatado por Protásio et al. (2013c) variou de $28 \%$ a $35 \%$. Neves et al. (2011) encontraram valores variando de $28 \%$ a $31 \%$ para clones de Eucalyptus spp. na idade de 68 meses. Logo, pode-se afirmar que, o teor de lignina total dos clones de Eucalyptus desse trabalho na idade de 46 meses foi baixo.

Tabela 3. Análise da interação clone x idade para o estoque de carbono, densidades energéticas e teores de lignina e holocelulose da madeira de Eucalyptus spp.

\begin{tabular}{|c|c|c|c|}
\hline \multirow{2}{*}{ Parâmetros avaliados } & \multirow{2}{*}{$\begin{array}{c}\text { Idade } \\
\text { (meses) }\end{array}$} & \multicolumn{2}{|c|}{ Clones } \\
\hline & & 0321 & 1277 \\
\hline \multirow{2}{*}{$\begin{array}{l}\text { Estoque de carbono na madeira } \\
\left(\mathrm{kg} \mathrm{m}^{-3}\right)\end{array}$} & 46 & $225 \mathrm{~b} \mathrm{~A}$ & 192 a A \\
\hline & 58 & $221 \mathrm{aA}$ & $238 \mathrm{~b} \mathrm{~B}$ \\
\hline \multirow{2}{*}{$\begin{array}{l}\text { Densidade energética base PCS }\left(\mathrm{DE}_{\mathrm{PCS}}\right) \\
\left(\mathrm{Gcal} \mathrm{m}^{-3}\right)\end{array}$} & 46 & $2,19 \mathrm{~b} \mathrm{~A}$ & 1,82 a A \\
\hline & 58 & 2,29 a B & $2,41 \mathrm{~b} \mathrm{~B}$ \\
\hline \multirow{2}{*}{$\begin{array}{l}\text { Densidade energética base PCI }\left(\mathrm{DE}_{\mathrm{PCI}}\right) \\
\left(\mathrm{Gcal} \mathrm{m}^{-3}\right)\end{array}$} & 46 & $2,02 \mathrm{~b} \mathrm{~A}$ & 1,68 a A \\
\hline & 58 & 2,14 a B & $2,25 \mathrm{~b} \mathrm{~B}$ \\
\hline \multirow{2}{*}{ Lignina total (\%) } & 46 & 27,8 a A & 26,1 a A \\
\hline & 58 & 29,3 a A & $32,8 \mathrm{~b} \mathrm{~B}$ \\
\hline \multirow{2}{*}{ Holocelulose (\%) } & 46 & 68,7 a B & 70,0 a B \\
\hline & 58 & $64,5 \mathrm{~b} \mathrm{~A}$ & 60,5 a A \\
\hline
\end{tabular}

Médias seguidas pela mesma letra minúscula, na linha, e maiúscula, na coluna, não diferem entre si a 5\% de significância pelo teste $\mathrm{F}$. 
Para a idade de 58 meses o clone 1277 apresentou o maior teor de lignina, correspondendo a um aumento de aproximadamente $12 \%$ em relação ao clone 0321 . O clone 1277 se destacou ainda pelo aumento do teor de lignina total com a idade e, consequentemente, diminuição do teor de holocelulose, corroborando com o encontrado por Neves et al. (2013).

Esses resultados são considerados positivos para o uso energético da madeira do clone 1277, na idade de 58 meses, pois a macromolécula de lignina é formada de uma matriz predominantemente aromática e tridimensional, constituída de unidades de fenilpropano $\mathrm{e}$, consequentemente, possui maior estabilidade térmica que os carboidratos da madeira. Isso confere à lignina menor perda de massa durante a pirólise e combustão direta (Raad et al., 2006; Yang et al., 2007; Pereira et al., 2013b; Protásio et al., 2012).

Dessa forma, a análise da quantidade e tipo da lignina são parâmetros fundamentais para indicar a utilização de um clone ou espécie de Eucalyptus para a combustão direta ou produção de carvão vegetal que atenda às especificações qualitativas e quantitativas das siderúrgicas (Pereira et al., 2012; 2013a; 2013b; Protásio et al., 2012; 2013a; 2013c; Neves et al., 2013).

Com base nessa discussão e nos resultados encontrados para a densidade básica, estoques de carbono e lignina total por volume e densidades energéticas, pode-se afirmar que o clone 1277, na idade de 58 meses, é o mais indicado para o uso bioenergético da madeira, principalmente para a conversão termoquímica.

\section{Efeitos simples de idade e clone para algumas características da madeira}

Pode ser observado na Tabela 4 que não foi encontrado efeito de clone para a composição química elementar $(\mathrm{C}, \mathrm{N}, \mathrm{H}$ e $\mathrm{O})$, bem como para as relações $\mathrm{C} / \mathrm{H}$ e $\mathrm{C} / \mathrm{N}$.
A madeira dos clones de Eucalyptus spp. avaliados apresentou apenas traços de enxofre $(0,01 \%)$, que não comprometem o seu uso bioenergético.

Tem sido reportado na literatura que independente da espécie, sítio, clone e idade, a composição química elementar da madeira de Eucalyptus, em base seca, é de aproximadamente $47 \%$ de carbono, $6 \%$ de hidrogênio, $46 \%$ de oxigênio, $0,12 \%$ de nitrogênio e $0,01 \%$ de enxofre (Neves et al., 2011; 2013; Reis et al., 2012; Pereira et al., 2013b; Protásio et al., 2013a; 2013c), ou seja, esses valores assemelham-se aos encontrados nesse estudo para os clones 0321 e 1277.

O carbono e o hidrogênio são os principais elementos químicos combustíveis, sendo assim, a concentração desses elementos irá definir a entalpia de combustão total ou o poder calorífico da biomassa, ou seja, a quantidade de energia térmica liberada pela oxidação desses átomos (Huang et al., 2009).

Entretanto, apesar da redução com a idade (Tabela 4 e Figura 2) dos teores de carbono e hidrogênio e, do aumento do teor de oxigênio, o poder calorífico superior (PCS) não foi afetado (média geral de $\left.4.626 \mathrm{kcal} \mathrm{kg}^{-1}\right)$. Possivelmente, isso ocorreu devido a baixa variação da constituição elementar das madeiras analisadas, sendo que resultados semelhantes são relatados na literatura (Neves et al., 2013; Protásio et al., 2013c).

Já o poder calorífico inferior aumentou com a idade $(\mathrm{Pr}>\mathrm{Fc}=0,0025)$, sendo encontrado $4.249 \mathrm{kcal} \mathrm{kg}^{-1}$ para a madeira de 46 meses e $4.342 \mathrm{kcal} \mathrm{kg}^{-1}$ para a de 58 meses. O poder calorífico inferior não inclui o calor latente da água presente nos produtos de combustão. Por isso, a diminuição do teor de hidrogênio e o aumento da relação $\mathrm{C} / \mathrm{H}$ de 7 para 8 na idade de 58 meses resultou no acréscimo do PCI.

Tabela 4. Resumo das análises de variância para a composição química elementar $(\mathrm{C}, \mathrm{H}, \mathrm{N}$ e $\mathrm{O})$ e as relações $\mathrm{C} / \mathrm{H}$ e $\mathrm{C} / \mathrm{N}$ da madeira dos clones de Eucalyptus spp.

\begin{tabular}{lccccccc}
\hline \multirow{2}{*}{ FV } & \multirow{2}{*}{ GL } & \multicolumn{6}{c}{ Quadrado médio } \\
\cline { 3 - 8 } & & $\mathbf{C ~ ( \% )}$ & $\mathbf{H ~ ( \% )}$ & $\mathbf{N ~ ( \% )}$ & $\mathbf{O}(\%)$ & $\mathbf{C} / \mathbf{H}$ & $\mathbf{C} / \mathbf{N}$ \\
\hline Clone $(\mathrm{C})$ & 1 & $3,677^{\text {ns }}$ & $0,066^{\text {ns }}$ & $0,0031^{\text {ns }}$ & $4,783^{\text {ns }}$ & $0,00001^{\text {ns }}$ & $7442,90^{\text {ns }}$ \\
Idade (I) & 1 & $23,547^{*}$ & $3,504^{*}$ & $0,0885^{*}$ & $58,768^{*}$ & $2,40490^{*}$ & $214662,34^{*}$ \\
C x I & 1 & $0,311^{\text {ns }}$ & $0,017^{\text {ns }}$ & $0,0007^{\text {ns }}$ & $0,477^{\text {ns }}$ & $0,00318^{\text {ns }}$ & $642,92^{\text {ns }}$ \\
Resíduo & 12 & 1,499 & 0,044 & 0,0012 & 1,989 & 0,00946 & 2462,26 \\
\hline Média geral & - & 46,6 & 6,1 & 0,18 & 46,7 & 8 & 306 \\
\hline CVe $(\%)$ & - & 2,63 & 3,42 & 19,06 & 3,02 & 1,27 & 16,23 \\
\hline
\end{tabular}

$\mathrm{FV}=$ fator de variação; $\mathrm{GL}$ = graus de liberdade; $\mathrm{CVe}=$ coeficiente de variação experimental (\%); $\mathrm{C} / \mathrm{H}$ = relação carbono/hidrogênio; $\mathrm{C} / \mathrm{N}=$ relação carbono/ nitrogênio; *significativo a $1 \%$ pelo teste $\mathrm{F}$; ns = não significativo a $5 \%$ pelo teste $\mathrm{F}$. 




Figura 2. Efeito da idade nos teores de carbono, hidrogênio e oxigênio da madeira dos clones de Eucalyptus avaliados.

O teor de nitrogênio decresceu com a idade, sendo encontrados os valores médios de $0,26 \%$ e $0,11 \%$ para as madeiras de 46 e 58 meses, respectivamente. Dessa forma, houve acréscimo da relação C/N de 190 para 422 para a madeira na idade de 58 meses.

Esse resultado pode ser considerado vantajoso, pois altos teores de $\mathrm{N}$ são indesejáveis se a madeira for utilizada como fonte de bioenergia, especialmente por processos de conversão termoquímica. Durante a combustão completa do material, esse elemento é convertido em óxidos tóxicos (NOx) que podem promover a formação de chuva ácida, acidificação de solos e corrosão nos equipamentos (Demirbas, 2004).

Quanto ao teor de cinzas na madeira, foi observada uma redução com a idade das árvores, pelo teste $\mathrm{F}$ ( $\mathrm{p}$-valor $<0,01$ ). Os teores de cinzas encontrados foram de $0,53 \%$ e $0,23 \%$ para as madeiras de 46 e 58 meses, respectivamente. O decréscimo dos teores de cinzas e de nitrogênio com a idade pode estar relacionado à diminuição da atividade fisiológica da árvore e é vantajoso para a produção de carvão vegetal e combustão direta da madeira.

No entanto, o teor de extrativos totais aumentou com a idade das árvores ( $\mathrm{p}$-valor $<0,01$ ), possivelmente devido ao processo de cernificação. Os valores obtidos foram de $3,17 \%$ e $6,20 \%$ para as idades de 46 e 58 meses, respectivamente. Dependendo da estabilidade térmica e da composição química, o maior teor de extrativos pode resultar no aumento do rendimento gravimétrico em carvão vegetal (Santos et al., 2011; Protásio et al., 2012).
$\mathrm{O}$ efeito de clone não influenciou (teste $\mathrm{F}$ a $5 \%$ de significância) o PCS (média de $4.626 \mathrm{kcal} \mathrm{kg}^{-1}$ e coeficiente de variação experimental de 1,07\%) e o PCI (média de $4.296 \mathrm{kcal} \mathrm{kg}^{-1}$ e coeficiente de variação experimental de 1,13\%). Dessa forma, o poder calorífico não pode ser considerado um parâmetro de seleção dos clones para a geração direta de energia. Contudo, conforme discutido anteriormente, a densidade energética variou consideravelmente, principalmente para o clone 1277 na idade de 58 meses.

De forma análoga, não há efeito clonal para os teores de extrativos totais (média de $4,7 \%$ e coeficiente de variação experimental de $8,36 \%$ ) e cinzas (média de $0,38 \%$ e coeficiente de variação experimental de 14,62\%).

\section{Qualidade e rendimentos do carvão vegetal}

O rendimento em carvão vegetal obtido nesse trabalho (Tabela 5) assemelha-se a outros trabalhos da literatura que utilizaram o mesmo procedimento laboratorial. Neves et al. (2011) e Protásio et al. (2013c) encontraram valores médios para o RGC de $31,5 \%$ e $32,0 \%$, respectivamente.

Apesar do aumento do teor de lignina total com a idade (Tabela 3), o rendimento gravimétrico em carvão vegetal não foi afetado consideravelmente (Tabela 5). Possivelmente, isso ocorreu devido a diferenças qualitativas no teor de lignina, ou seja, a relação siringil/guaiacil ( $\mathrm{S} / \mathrm{G})$. Geralmente, a conversão de madeira em carvão vegetal aumenta com a diminuição da relação siringil/guaiacil, uma vez que isso promove maior resistência da madeira à degradação térmica, pela presença de estruturas mais condensadas (Castro et al., 2013; Pereira et al., 2013b).

O rendimento em carbono fixo também foi pouco influenciado pela idade ou clone (Tabela 5), assemelhandose a média geral encontrada na literatura para clones de Eucalyptus, ou seja, 25\% (Neves et al., 2011; Reis et al., 2012; Protásio et al., 2013b). O rendimento em carbono fixo foi calculado pelo produto entre o teor de carbono fixo e o rendimento gravimétrico em carvão vegetal e sabe-se que essas duas últimas variáveis possuem correlação negativa (Reis et al., 2012), o que explica os resultados encontrados.

$\mathrm{O}$ rendimento em líquido pirolenhoso diminuiu em aproximadamente $17 \%$ com o aumento da idade; enquanto, o rendimento em gases não condensáveis aumentou em aproximadamente 30\%. Possivelmente, isso ocorreu devido à redução do teor de holocelulose na madeira (Tabela 3) com a maturidade das árvores. 
Tabela 5. Balanço de massa e energia das carbonizações da madeira dos clones de Eucalyptus spp.

\begin{tabular}{|c|c|c|c|c|c|c|c|}
\hline Idade & Clone & RGC (\%) & RLP (\%) & RGNC (\%) & RCF (\%) & $\mathrm{RE}_{\mathrm{PCS}}(\%)$ & $\mathrm{RE}_{\mathrm{PCI}}(\%)$ \\
\hline \multirow{2}{*}{46 meses } & 0321 & 31,7 & 47,3 & 21,0 & 24,4 & 55,1 & 58,4 \\
\hline & 1277 & 31,4 & 46,6 & 22,0 & 24,7 & 52,4 & 55,5 \\
\hline \multirow{2}{*}{58 meses } & 0321 & 31,6 & 38,0 & 30,4 & 25,5 & 51,8 & 55,5 \\
\hline & 1277 & 32,2 & 42,4 & 25,4 & 25,3 & 53,0 & 55,6 \\
\hline \multicolumn{2}{|c|}{ Média } & 31,7 & 43,6 & 24,7 & 25,0 & 53,1 & 56,3 \\
\hline \multicolumn{2}{|c|}{ CV (\%) } & 1,01 & 9,84 & 17,19 & 2,06 & 2,71 & 2,58 \\
\hline
\end{tabular}

RGC, RLP, RGNC e RCF = rendimentos gravimétricos em carvão vegetal, líquido pirolenhoso, gases não condensáveis e carbono fixo, respectivamente; $\mathrm{RE}_{\mathrm{PCS}}$ e $\mathrm{RE}_{\mathrm{PCI}}=$ rendimentos energéticos base PCS e PCI, respectivamente; $\mathrm{CV}=$ coeficiente de variação.

O efeito de clone e idade nos rendimentos energéticos foi pouco pronunciado, possivelmente devido à temperatura final de carbonização ter sido a mesma para todas as carbonizações realizadas. Esse parâmetro do processo influencia consideravelmente o balanço de massa e energia na conversão termoquímica da madeira em carvão vegetal.

O rendimento energético calculado com base no PCI foi maior que o rendimento energético obtido com base no PCS. Isso pode ser explicado devido à volatilização de hidrogênio da constituição química da madeira durante a pirólise e a maior concentração de carbono no carvão, conforme pode ser constatado analisando-se os trabalhos de Pereira et al. (2013b) e Protásio et al. (2013b; 2013c; 2014). Logo, o PCS e PCI do carvão vegetal tendem a ser semelhantes e a relação entre o PCI do carvão vegetal e da madeira é maior que a relação entre o PCS desses combustíveis, conforme relatado por Protásio et al. (2014).

As perdas energéticas com os gases condensáveis e não condensáveis foram em média de $46,9 \%$ (base PCS). Dessa forma, visando aumentar a eficiência do processo de conversão da madeira em carvão vegetal, pode-se optar por aproveitar os gases combustíveis da pirólise para a geração de energia para o próprio sistema de carbonização (Cardoso et al., 2010; Oliveira et al., 2013).

Diferentemente do encontrado para a densidade básica e densidades energéticas da madeira, não foi encontrada influência da idade na DRA e nas densidades energéticas do carvão vegetal do clone 1277 (Figuras 3a e 3b). No entanto, para o clone 0321 foi observado acréscimo da densidade aparente, das densidades energéticas e do estoque de carbono fixo do carvão vegetal com a idade.

Para clones comerciais de Eucalyptus, aos 68 meses, Neves et al. (2011) encontraram densidade aparente média do carvão vegetal de $344 \mathrm{~kg} \mathrm{~m}^{-3}$. Esse valor é inferior ao observado para os clones 1277 e 0321, nas idades de 46 meses e 58 meses, e demonstra o potencial de uso energético dos carvões avaliados, pois foram produzidos com madeiras mais jovens.

A densidade do carvão é uma importante propriedade a ser avaliada, pois quanto maior o seu valor, maior será a sua resistência mecânica e maiores serão os estoques energéticos e de carbono fixo. Logo, mais propício será o carvão vegetal para ser utilizado como agente de dupla finalidade nos altos fornos siderúrgicos.

Nota-se que o carvão vegetal apresentou maior densidade energética que a madeira que lhe deu origem (Tabela 3 e Figura 3b), corroborando com o trabalho de Pereira et al. (2012) para um clone de Eucalyptus spp. na idade de 90 meses. Para o clone 1277 na idade de 46 meses esse incremento nas densidades energéticas foi mais pronunciado, sendo em média $67 \%$ e $77 \%$ para a $\mathrm{DE}_{\mathrm{PCS}}$ e $\mathrm{DE}_{\mathrm{PCI}}$, respectivamente.

Os teores de materiais voláteis e carbono fixo, bem como o poder calorífico do carvão vegetal, não foram afetados pelos diferentes clones ou idades avaliadas (Tabela 6). Isso é um indicativo da baixa influência da madeira nas características químicas e energéticas do carvão vegetal e pode ser explicado pela temperatura final de carbonização ter sido constante. Protásio et al. (2013a) relataram o mesmo resultado para o carvão vegetal produzido a partir de clones de Eucalyptus sp. aos 42 meses.

Já o teor de cinzas no carvão vegetal reduziu com a idade dos clones, ou seja, a mesma tendência encontrada para a madeira e discutida anteriormente. Isso é uma vantagem que, aliada ao teor de carbono fixo superior a $75 \%$, qualifica o carvão vegetal dos clones 0321 e 1277, na idade de 58 meses, como mais propícios para uso como agente de dupla finalidade na siderurgia. 

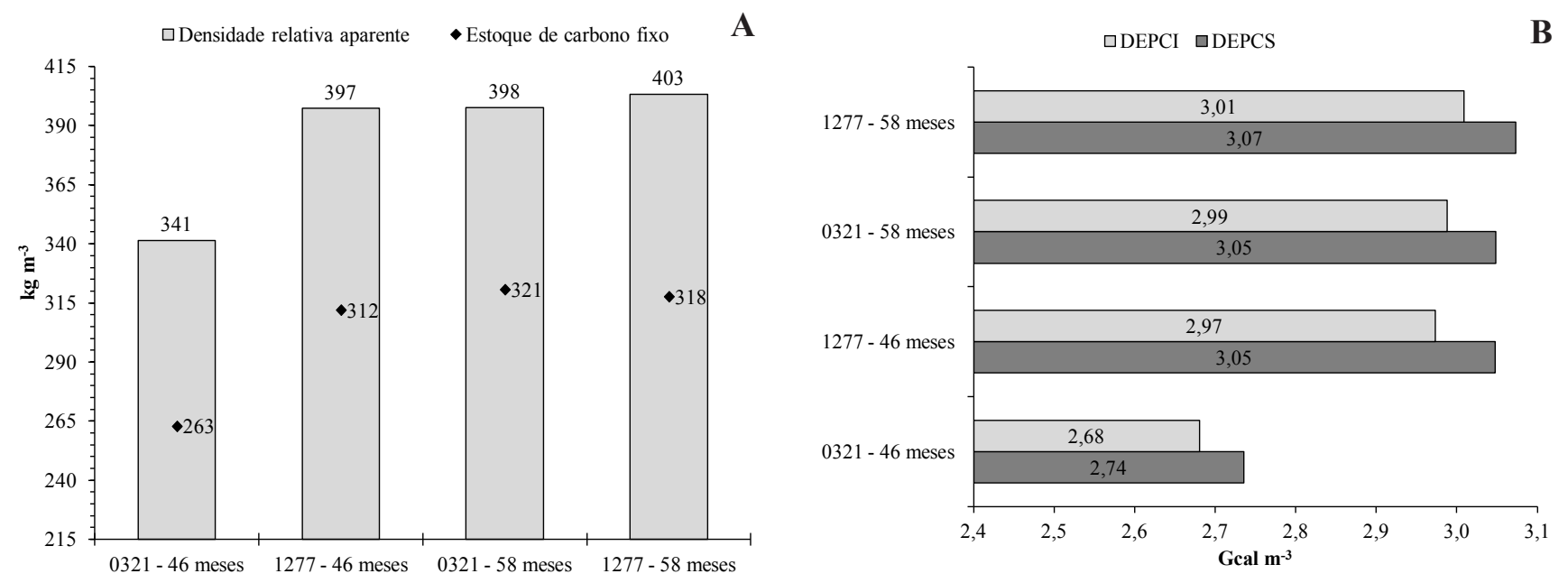

Figura 3. (A) Densidade relativa aparente, estoque de carbono fixo por volume e (B) densidades energéticas $\left(\mathrm{DE}_{\mathrm{PCI}}\right.$ e $\left.\mathrm{DE}_{\mathrm{PCS}}\right)$ do carvão vegetal.

Tabela 6. Análise química imediata e poderes caloríficos do carvão vegetal oriundo da madeira de clones de Eucalyptus spp.

\begin{tabular}{|c|c|c|c|c|c|c|}
\hline Idade & Clone & TMV (\%) & TCZ (\%) & TCF (\%) & PCS (kcal kg-1) & PCI (kcal kg-1) \\
\hline \multirow{2}{*}{46 meses } & 0321 & 21,7 & 1,2 & 77,0 & 8017 & 7855 \\
\hline & 1277 & 20,0 & 1,5 & 78,6 & 7672 & 7485 \\
\hline \multirow{2}{*}{58 meses } & 0321 & 18,5 & 0,9 & 80,7 & 7669 & 7515 \\
\hline & 1277 & 20,5 & 0,7 & 78,8 & 7621 & 7462 \\
\hline \multicolumn{2}{|c|}{ Média } & 20,2 & 1,1 & 78,8 & 7745 & 7579 \\
\hline \multicolumn{2}{|c|}{ CV (\%) } & 6,67 & 35,28 & 1,90 & 2,36 & 2,44 \\
\hline
\end{tabular}

TMV, TCZ e TCF = teores de materiais voláteis, cinzas e carbono fixo; PCS e PCI = poderes caloríficos superior e inferior; CV = coeficiente de variação.

Pela análise multivariada, percebe-se que os dois primeiros componentes principais obtidos explicaram $88,2 \%$ da variância total dos dados (Figura 4). Portanto, as informações mais relevantes dos dados amostrais originais estão contidas nesses dois componentes.

Observou-se que, quanto maiores os valores de densidade relativa aparente, teor de carbono fixo e rendimento em gases não condensáveis do carvão vegetal, maiores serão os escores do componente principal 1. Para o componente principal 2, encontrouse autovetor positivo e expressivo para o rendimento gravimétrico em carvão vegetal e negativo para o teor de cinzas.

Considerando-se os valores médios obtidos para a densidade aparente, teores de carbono fixo e materiais voláteis e o rendimento gravimétrico em carvão vegetal, pode-se afirmar que os clones 1277 e 0321 são mais propícios para serem utilizados na produção de carvão vegetal de uso siderúrgico na idade de 58 meses. Esse biorredutor produzido a partir dessas madeiras, especialmente do clone 1277, apresentou menor teor de cinzas que o carvão produzido com a madeira de 46 meses, conforme pode ser visualizado na Figura 4.

Contudo, o rendimento em gases não condensáveis para o carvão produzido com a madeira de 58 meses foi maior. Isso pode ser evidenciado analisando-se os maiores escores obtidos para o componente principal 1. Logo, a conversão da madeira de 58 meses de idade em carvão vegetal poderá resultar em maiores emissões de gases combustíveis, bem como de gases causadores de efeito estufa para atmosfera. Contudo, isso pode ser amenizado com um sistema fornofornalha (Cardoso et al., 2010; Oliveira et al., 2013). 


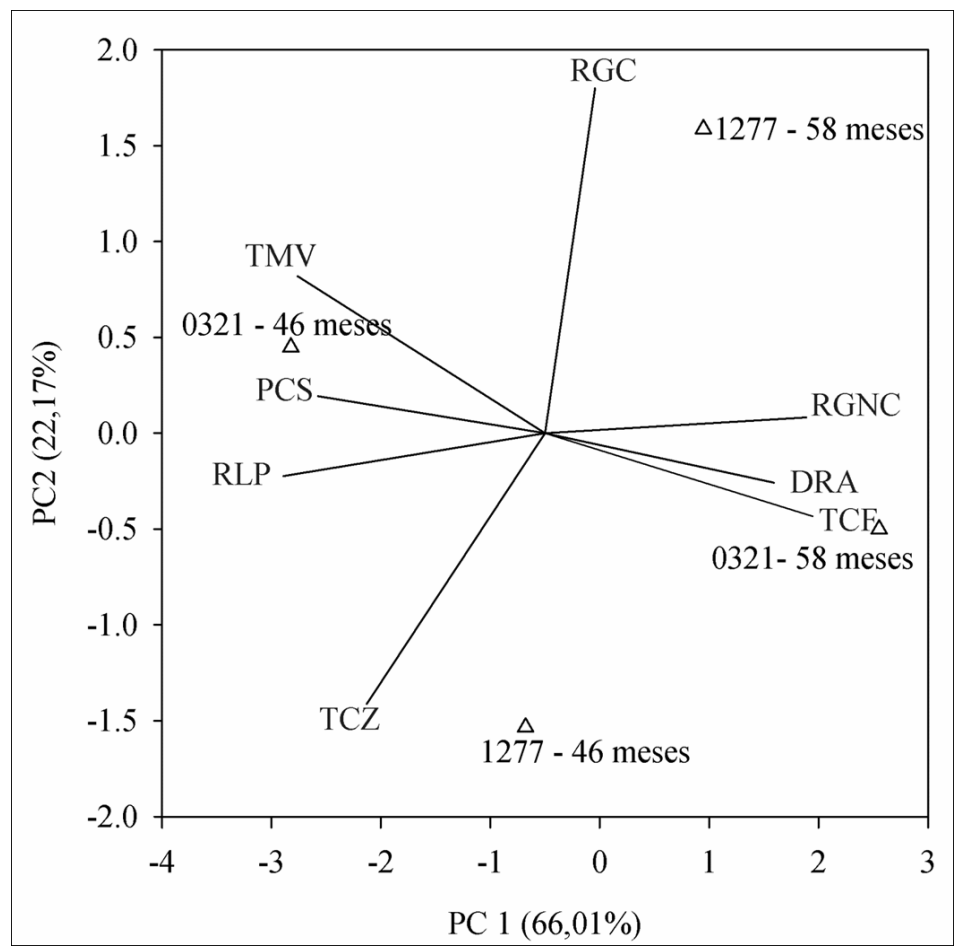

Figura 4. Escores e autovetores dos dois primeiros componentes principais (PC1 e PC2). DRA = densidade relativa aparente; RGC, RLP e RGNC = rendimentos gravimétricos em carvão vegetal, líquido pirolenhoso e gases não condensáveis; TMV, TCZ e TCF = teores de materiais voláteis, cinzas e carbono fixo; PCS = poder calorífico superior.

\section{Conclusões}

O clone 1277, na idade de 58 meses, é o mais indicado para a produção de carvão vegetal siderúrgico e combustão direta da madeira, pois apresenta maiores densidades básica e energética e estoques de carbono e lignina total por volume.

$\mathrm{O}$ aumento da idade resulta na redução dos teores de carbono, hidrogênio, nitrogênio e cinzas e acréscimo dos teores de oxigênio e extrativos totais e do poder calorífico inferior da madeira. Já o efeito de clone não foi pronunciado para essas características.

O efeito clonal e da idade, de maneira geral, não influencia os teores de carbono fixo e materiais voláteis, os poderes caloríficos, o rendimento gravimétrico em carvão vegetal e as perdas energéticas da carbonização.

\section{Agradecimentos}

Ao CNPq, pela concessão das bolsas de mestrado (processo 132431/2013-0) e de doutorado (processo 141439/2014-9) do primeiro autor, e à Saint-Gobain Pam Bioenergia LTDA., pela parceria financeira e doação das árvores.

\section{Referências}

AMERICAN SOCIETY FOR TESTING MATERIALS. D176284: standard test method for chemical analysis of wood charcoal. Philadelphia, 2007. 2 p.

ASSIS, M. R.; PROTÁSIO, T. P.; ASSIS, C. O.; TRUGILHO, P. F.; SANTANA, W. M. S. Qualidade e rendimentos do carvão vegetal de um clone híbrido de Eucalyptus grandis x Eucalyptus urophylla. Pesquisa Florestal Brasileira, Colombo, v. 32, n. 71, p. 291-302, 2012. DOI: http://dx.doi.org/10.4336/2012.pfb.32.71.291

ASSOCIAÇÃO BRASILEIRA DE NORMAS TÉCNICAS. NBR 11941: madeira: determinação da densidade básica. Rio de Janeiro, 2003a. 6 p.

ASSOCIAÇÃO BRASILEIRA DE NORMAS TÉCNICAS. NBR 14853: madeira: determinação do material solúvel em etanol-tolueno e em diclorometano e em acetona. Rio de Janeiro, 2010. 3 p.

ASSOCIAÇÃO BRASILEIRA DE NORMAS TÉCNICAS. NBR 8633: carvão vegetal: determinação do poder calorífico. Rio de Janeiro, 1984. 13 p.

ASSOCIAÇÃO BRASILEIRA DE NORMAS TÉCNICAS. NBR 13999: papel, cartão, pastas celulósicas e madeira: determinação do resíduo (cinza) após a incineração a $525^{\circ} \mathrm{C}$. Rio de Janeiro, 2003b. 4 p.

ANUÁRIO estatístico da ABRAF 2013: ano base 2012. Brasília, DF: ABRAF, 2013. 148 p. 
CARDOSO, M. T.; DAMÁSIO, R. A. P.; CARNEIRO, A. C. O.; JACOVINE, L. A. G.; VITAL, B. R.; BARCELOS, D. C. Construção de um sistema de queima de gases da carbonização para redução da emissão de poluentes. Cerne, Lavras, v. 16, Suplemento, p. 115124, 2010.

CASTRO, A. F. N. M.; CASTRO, R. V. O.; CARNEIRO, A. C. O.; LIMA, J. E.; SANTOS, R. C.; PEREIRA, B. L. C.; ALVES, I. C. N. Análise multivariada para seleção de clones de eucalipto destinados à produção de carvão vegetal. Pesquisa Agropecuária Brasileira, Brasília, DF, v. 48, n. 6, p. 627-635, 2013.

COUTO, A. M.; PROTÁSIO, T. P.; TRUGILHO, P. F.; NEVES, T. A.; SÁ, V. A. Multivariate analysis applied to evaluation of Eucalyptus clones for bioenergy production. Cerne, Lavras, v. 19, n. 4, 2013.

DEMIRBAS, A. Combustion characteristics of different biomass fuels. Progress in Energy and Combustion Science, v.30, n.2, p.219-230, 2004.

DOWNES, G. M.; HUDSON, I. L.; RAYMOND, C. A.; DEAN, G. H.; MICHELL, A. J.; SCHIMLECK, R.; EVANS, R.; MUNERI, A. Sampling plantation eucalypts for wood and fibre properties. Collingwood: CSIRO. Australia, 1997. 126 p.

EMPRESA DE PESQUISA ENERGÉTICA. Balanço energético nacional 2013: ano base 2012. Rio de Janeiro, 2013. 288 p.

FERREIRA, E.B.; CAVALCANTI, P.P.; NOGUEIRA, D.A. ExpDes: experimental designs package. $\mathbf{R}$ package version 1.1.2. 2013. Disponível em: <http://cran.r-project.org/web/packages/ExpDes/ index.html $>$. Acesso em: 14 jul. 2013.

GOLDSCHIMID, O. Ultraviolet spectra. In: SARKANEN, K. V.; LUDWIG, C. H. (Ed.). Lignins: occurrence, formation, structure and reactions. New York: J. Wiley, 1971. p. 241-266.

GOMIDE, J. L.; DEMUNER, B. J. Determinação do teor de lignina em material lenhoso: método Klason modificado. O Papel, São Paulo, v. 47, n. 8, p. 36-38, 1986.

HUANG, C.; HAN, L.; YANG, Z.; LIU, X. Ultimate analysis and heating value prediction of straw by near infrared spectroscopy. Waste Management, v.29, n.6, p.1793-1797, 2009.

NEVES, T. A.; PROTÁSIO, T. P.; COUTO, A. M.; TRUGILHO, P. F.; SILVA, V. O.; VIEIRA, C. M. M. Avaliação de clones de Eucalyptus em diferentes locais visando à produção de carvão vegetal. Pesquisa Florestal Brasileira, Colombo, v. 31, n. 68, p. 319-330, 2011. DOI: 10.4336/2011.pfb.31.68.319

NEVES, T. A.; PROTÁSIO, T. P.; TRUGILHO, P. F.; VALLE, M. L. A.; SOUSA, L. C.; VIEIRA, C. M. Qualidade da madeira de clones de Eucalyptus em diferentes idades para a produção de bioenergia. Revista de Ciências Agrárias, Belém, v. 56, n. 2, p. 139-148, 2013.

OLIVEIRA, A. C.; CARNEIRO, A. C. O.; PEREIRA, B. L. C.; VITAL, B. R.; CARVALHO, A. M. M. L.; TRUGILHO, P. F.; DAMÁSIO, R. A. Otimização da produção do carvão vegetal por meio do controle de temperaturas de carbonização. Revista Árvore, Viçosa, MG, v. 37, n. 3, p. 557-566, 2013.
PEREIRA, B. L. C.; CARNEIRO, A. C. O.; CARVALHO, A. M. M. L.; TRUGILHO, P. F.; MELO, I. C. N. A.; OLIVEIRA, A. C. Estudo da degradação térmica da madeira de Eucalyptus através de termogravimetria e calorimetria. Revista Árvore, Viçosa, MG, v. 37, n. 3, p. 567-576, 2013 a.

PEREIRA, B. L. C.; CARNEIRO, A. C. O.; CARVALHO, A. M. M. L.; COlODETTE, J. L.; OliVEIRA, A. C.; FONTES, M. P. F. Influence of chemical composition of Eucalyptus wood on gravimetric yield and charcoal properties. Bioresources, North Carolina, v. 8, n. 3, p. 4574-4592, 2013 b.

PEREIRA, B.L.C.; OLIVEIRA, A.C.; CARVALHO, A.M.M.L.; CARNEIRO, A.C.O.; SANTOS, L.C.; VITAL, B.R. Quality of wood and charcoal from Eucalyptus clones for ironmaster use. International Journal of Forestry Research, New York, v. 2012, p. 1-8, 2012.

PROTÁSIO, T.P.; BUFALINO, L.; TONOLI, G.H.D.; GUIMARÃES JUNIOR, M.; TRUGILHO, P.F.; MENDES, L.M. Brazilian lignocellulosic wastes for bioenergy production: characterization and comparison with fossil fuels. Bioresources, v.8, n.1, p.11661185, 2013a.

PROTÁSIO, T. P.; COUTO, A. M.; REIS, A. A.; GODINHO, T. P.; TRUGILHO, P. F. Potencial siderúrgico e energético do carvão vegetal de clones de Eucalyptus spp. aos 42 meses de idade. Pesquisa Florestal Brasileira, Colombo, v. 33, n. 74, p. 137-149, 2013 b.

PROTÁSIO, T. P.; COUTO, A. M.; REIS, A. A.; TRUGILHO, P. F. Seleção de clones de Eucalyptus para a produção de carvão vegetal e bioenergia por meio de técnicas univariadas e multivariadas. Scientia Forestalis, Piracicaba, v. 42, n. 97, p. 15-28, $2013 \mathrm{c}$.

PROTÁSIO, T. P.; TRUGILHO, P. F.; NAPOLI, A.; SILVA, M. G.; COUTO, A. M. Mass and energy balance in the carbonization of babassu nutshell as affected by temperature. Pesquisa Agropecuária Brasileira, Brasília, DF, v. 49, n. 3, p. 189-196, 2014.

PROTÁSIO, T. P.; TRUGILHO, P. F.; NEVES, T. A.; VIEIRA, C. M. M. Análise de correlação canônica entre características da madeira e do carvão vegetal de Eucalyptus. Scientia Forestalis, Piracicaba, V. 40, n. 95, p. 317-326, 2012.

R CORE TEAM. R: a language and environment for statistical computing. Vienna: R Foundation for Statistical Computing, 2013. Disponível em: <http://www.R-project.org/>. 14 jul. 2013.

RAAD, T. J.; PINHEIRO, P. C. C.; YOSHIDA, M. I. Equação geral de mecanismos cinéticos da carbonização do Eucalyptus spp. Cerne, Lavras, v. 12, n. 2, p. 93-106, 2006.

REIS, A. A.; PROTÁSIO, T. P.; MELO, I. C. N. A.; TRUGILHO, P. F.; CARNEIRO, A. C. Composição da madeira e do carvão vegetal de Eucalyptus urophylla em diferentes locais de plantio. Pesquisa Florestal Brasileira, Colombo, v. 32, n. 71, p. 277-290, 2012. DOI: http://dx.doi.org/10.4336/2012.pfb.32.71.277

SANTOS, L. C.; CARVAlHO, A. M. M. L.; PEREIRA, B. L. C.; OliveIRA, A. C.; CARNEIRO, A. C. O.; TRUGILHO, P. F. Propriedades da madeira e estimativas de massa, carbono e energia de clones de Eucalyptus plantados em diferentes locais. Revista Árvore, Viçosa, MG, v. 36, n. 5, p. 971-980, 2012a. 
SANTOS, R. C.; CARNEIRO,A. C. O.; TRUGILHO, P. F.; MENDES, L. M.; CARVALHO, A. M. M. L. Análise termogravimétrica em clones de eucalipto como subsídio para a produção de carvão vegetal. Cerne, Lavras, v. 18, n. 1, p. 143-151, 2012b.

SANTOS, R. C.; CARNEIRO, A. C. O.; CASTRO, A. F. M.; CASTRO, R. V. O.; BIANCHE, J. J.; SOUZA, M. M.; CARDOSO,

M. T. Correlações entre os parâmetros de qualidade da madeira e do carvão vegetal de clones de eucalipto. Scientia Forestalis, Piracicaba, SP, v. 39, n. 90, p. 221-230, 2011.
TRUGILHO, P. F. Densidade básica e estimativa de massa seca e de lignina na madeira em espécies de Eucalyptus. Ciência e Agrotecnologia, Lavras, v. 33, n. 5, 2009.

YANG, H.; YAN, R.; CHEN, H.; LEE, D. H.; ZHENG, C. Characteristics of hemicellulose, cellulose and lignin pyrolysis. Fuel, London, v. 86, n. 12/13, p. 1781-1788, 2007. 
